\title{
Search for Possible Associations of FTO Gene Polymorphic Variants with Metabolic Syndrome, Obesity and Body Mass Index in Schizophrenia Patients
}

\author{
Anastasiia S Boiko, (D) ${ }^{1, *}$ Ivan V \\ Pozhidaev, (ID) ${ }^{\prime} *$ Diana Z \\ Paderina, (ID) Anna $V$ \\ Bocharova, (D) ${ }^{2}$ Irina A \\ Mednova, (D) ${ }^{\prime}$ Olga Yu \\ Fedorenko, (D) 'Elena G \\ Kornetova, (1) ${ }^{3,4}$ Anton JM \\ Loonen, (iD $)^{5}$ Arkadiy V Semke, (iD $)^{3}$ \\ Nikolay A Bokhan, $\mathbb{D}^{6,7}$ Svetlana A \\ Ivanova $(\mathbb{D})^{1,7}$
}

'Molecular Genetics and Biochemistry Laboratory, Mental Health Research Institute, Tomsk National Research Medical Center of the Russian Academy of Sciences, Tomsk, Russian Federation; ${ }^{2}$ Laboratory of Evolutionary Genetics, Research Institute of Medical Genetics, Tomsk National Research Medical Center of the Russian Academy of Sciences, Tomsk, Russian Federation; ${ }^{3}$ Endogenous Disorders Department, Mental Health Research Institute, Tomsk Nationa Research Medical Center of the Russian Academy of Sciences, Tomsk, Russian Federation; ${ }^{4}$ University Hospital, Siberian State Medical University, Tomsk, Russian Federation; ${ }^{5}$ unit of Pharmacotherapy, Epidemiology \& Economics, Groningen Research Institute of Pharmacy, University of Groningen, Groningen, the Netherlands: ${ }^{6}$ Addictive Disorders Department, Mental Health Research Institute, Tomsk Nationa Research Medical Center of the Russian Academy of Sciences, Tomsk, Russian Federation;

${ }^{7}$ Psychiatry, Addiction Psychiatry and Psychotherapy Department, Siberian State Medical University, Tomsk, Russian Federation

*These authors contributed equally to this work

Correspondence: Anton JM Loonen Unit of Pharmacotherapy, Epidemiology \& Economics, Groningen Research Institute of Pharmacy, University of Groningen, Antonius Deusinglaan I, Groningen, 97I3AV, the Netherlands

Tel +3I 503637576

Email a.j.m.loonen@rug.nl
Purpose: Metabolic syndrome (MetS) is characterized by abdominal obesity, hyperglycaemia, dyslipidaemia and hypertension. FTO gene has been implicated in the pathogenesis of obesity, but the available scientific data concerning their relationship to antipsychotic druginduced obesity and metabolic syndrome is still incomplete and inconsistent, which indicates that continuing the investigation of this gene's role is necessary.

Patients and Methods: In the present study, 517 patients with schizophrenia underwent antipsychotic drug treatment, and two groups were identified: patients with MetS and without MetS. Genotyping of 6 SNPs in the FTO gene was performed, and the results analyzed using R-programme.

Results: We performed a statistical analysis to identify possible associations of the frequencies of genotypes and alleles of the studied polymorphisms with the presence of metabolic syndrome in schizophrenia patients, with the presence of abdominal obesity, and with an increased body mass index. The rs7185735 polymorphism did not meet the Hardy-Weinberg criterion and was excluded. After correcting for differences in age, gender and duration of illnesses, none of the variants was shown to be related to metabolic syndrome or abdominal obesity, but rs9939609, rs1421085, rs3751812 and rs8050136 were associated with body mass index.

Conclusion: The present study provides additional support for these SNP's roles as a pharmacogenetic biomarker that may become useful in the framework of the personalized medicine approach.

Keywords: schizophrenia, gene polymorphism, body weight, waist circumference, fat mass and obesity associated gene

\section{Introduction}

Antipsychotics are an important therapeutic agent for patients with schizophrenia and bipolar disorder, but long-term usage of these drugs increases the risk of developing type 2 diabetes mellitus, hyperlipidemia and hypertension. ${ }^{1-3}$ Together with central obesity, these phenomena form the so-called Metabolic Syndrome (MetS), which is a clustering of well-known cardiovascular risk factors. ${ }^{4,5}$ Apart from increasing the likelihood of serious cardiovascular ${ }^{6,7}$ and malignant pathology, ${ }^{8,9}$ significant weight gain can also affect compliance and a decrease in the quality of life of patients with schizophrenia, since, in addition to the stigma of 
schizophrenia, the stigma of obesity is added. ${ }^{10}$ The prevalence of MetS and obesity in patients with schizophrenia is high, so according to studies, the incidence of MetS in schizophrenia patients taking antipsychotics ranges from $28 \%{ }^{11}$ to $46 \%,{ }^{12}$ and obesity from $16.4 \%{ }^{13}$ to $48.9 \%$. ${ }^{14}$

The FTO gene was identified in 1999 as "Fatso" when tracing the genes lost in a mouse mutant with fused toes (Ft mutant). ${ }^{15,16}$ After two independent Genome-Wide Associations Studies (GWAS) found that this gene had something to do with obesity, ${ }^{17,18}$ a flood of research has begun to further specify its role, now labelled as "fat mass and obesity associated" (FTO) gene. ${ }^{19,20}$ FTO protein function was first described as an N6-methyladenosine (m6A) demethylase dependent on iron and 2-oxoglutarate. ${ }^{21,22}$ Then, the FTO-deficient mouse model was studied to understand its physiological function. These mice display postnatal growth retardation and reduced food intake, with a reduction of adipose tissue. ${ }^{23,24}$ In line with this, overexpression of FTO induced an increase of adipose tissue. ${ }^{25}$ The protein coded for by the FTO gene can be considered one of the most important enzymes that remove the methyllabelling of N6-methyladenosine residues from the RNA molecule. ${ }^{26,27}$ The activity of this RNA demethylase partly determines the post-transcriptional gene expression regulation and thus influences numerous (patho)physiological functions, ${ }^{26,27}$ linking the FTO gene to cancer, obesity and neuropsychiatric disorders. ${ }^{28-30}$ However, although the human FTO gene, which is located on chromosome $16 \mathrm{q} 12.2,{ }^{31}$ encodes for RNA demethylase, this is probably not its primary role in causing obesity. ${ }^{32}$ In contrast, FTO intronic variant rs1421085, which is the causal single nuclear polymorphism (SNP) associated with obesity, does not regulate FTO expression. ${ }^{32}$ In fact, this variant disrupts the binding site of the ARID5B repressor, which regulates IRX3 and IRX5 expression, homeobox genes involved in morphogenesis during early embryonic development. ${ }^{32-35} \mathrm{It}$ has been suggested that this results in a shift between the development of beige (energy-wasting) and white (energystoring) adipocytes. ${ }^{34}$ Although a critical significance of IRX3 in the differentiation of preadipocytes has been demonstrated, ${ }^{36}$ other mechanisms also exist that may be applicable.

The significance of polymorphisms of the FTO gene for obesity has been extensively investigated. In the first GWAS of the relationship between BMI and the FTO gene, rs9939609 was chosen to represent ten variants of the gene's first intron. ${ }^{17}$ This variant was also found by Scuteri et al, but in their study, ${ }^{18}$ rs9930506 showed the greatest association with increased BMI, hip circumference and body weight. At approximately the same time, obesity was found with a case-control design to be associated with rs1421085 and rs17817449 in different patient populations. ${ }^{31}$ The findings for rs9939609, rs 1421085, and rs17817449 were later confirmed in a Mexican population $^{37}$ and for rs9939609 with type 2 diabetes. ${ }^{38}$ In a recent meta-analysis of GWASs, 29 SNPs in FTO were significantly associated with lean soft tissue (nonfat, nonbone), including rs9939609, rs9930506, rs1421085, and rs17817449. ${ }^{39}$ Rs1421085 is in perfect linkage disequilibrium with rs $1558902,{ }^{34}$ which in turn is the most associated SNP in the GWAS of Locke et al. ${ }^{40}$ The rs 1861868 variant is much less well studied, but an association with BMI in Old Order Amish individuals, ${ }^{41}$ as well as Spanish, ${ }^{42}$ German Sorbian, ${ }^{43}$ African American, ${ }^{44}$ Emirati, ${ }^{45}$ and Saudi populations ${ }^{46}$ has been described.

The involvement of the FTO gene in the development of obesity may be clear, but its contribution concerning weight gain in users of antipsychotic drugs is less evident. ${ }^{4-51}$ An association between variants of the FTO gene is not observed by all researchers and is rather modest in many other cases. The relationship between polymorphisms of the FTO gene and metabolic syndrome has only once been investigated. ${ }^{52}$

The previous uncertainties led us to investigate the association between six variants of the FTO gene (rs7185735, rs9939609, rs1421085, rs1861868, rs3751812, rs8050136) and BMI or MetS in schizophrenia patients from three hospitals in Siberia.

\section{Materials and Methods Study Subjects}

The study complied with the Declaration of Helsinki (1975, revised in Fortaleza, Brazil, 2013). The study protocol was approved by the Bioethical Committee of the Mental Health Research Institute of the Tomsk National Research Medical Center of the Russian Academy of Sciences (Protocol 187, approval on 24.04.2018). The patient population and design of the study particular have been described before. ${ }^{53,54}$ After obtaining informed consent, we recruited 517 inpatients with schizophrenia from the clinics of the Research Institute of Mental Health of the Tomsk National Research Medical Center, the Tomsk Clinical Psychiatric Hospital, the Hospital of the Siberian State Medical University, the Kemerovo Regional Clinical 
Psychiatric Hospital and the N.N. Solodnikova Clinical Psychiatric Hospital of Omsk in the Russian Federation.

The study included patients with a verified diagnosis of schizophrenia according to ICD-10 (International Classification of Diseases $10^{\text {th }}$ revision) $)^{55}$ criteria, age 18-65 years, the patient's informed consent, Caucasian appearance, the absence of severe organic pathology or somatic disorders in the stage of decompensation, and usage of a stable antipsychotic treatment. The severity of psychopathology was measured by applying the Positive And Negative Syndrome Scale (PANSS). ${ }^{56}$

The antipsychotic and concomitant therapy received at the time of the examination (drugs, dosages used, duration of current drug use) were assessed, as well as previous antipsychotic and concomitant somatic therapy during the preceding six months. The study used a chlorpromazine equivalent (CPZeq) daily dosage to standardize the dose, efficacy, and side effects of antipsychotics. ${ }^{57}$

MetS was diagnosed according to the criteria of the International Diabetes Federation (IDF, 2005) ${ }^{58}$ including the definition of abdominal obesity (waist circumference more than $94 \mathrm{~cm}$ in men, more than $80 \mathrm{~cm}$ in women) and the presence of any two of the following four signs:

1. Concentration of triglycerides (TG) above 1.7 $\mathrm{mmol} / \mathrm{L}$ or lipid-lowering therapy;

2. Concentration of high-density lipoproteins (HDL) less than $1.03 \mathrm{mmol} / \mathrm{L}$ in men and $1.29 \mathrm{mmol} / \mathrm{L}$ in women;

3. Blood pressure (BP) greater than or equal to $130 /$ $85 \mathrm{~mm} \mathrm{Hg}$ or usage of antihypertensive therapy;

4. The concentration of glucose in the blood serum is higher than or equal to $5.6 \mathrm{mmol} / \mathrm{L}$ or previously diagnosed type 2 diabetes mellitus.

Anthropometric parameters included waist circumference, height and body mass index (BMI).

\section{Laboratory Examination Blood Sampling}

Blood samples were taken by antecubital venipuncture in vacutainer tubes with a clot activator (CAT) (to obtain serum) or with EDTA (to isolate genomic DNA by the standard phenol-chloroform method). Blood samples with CAT were centrifuged for $30 \mathrm{~min}$ at $2000 \mathrm{~g}$ at four ${ }^{\circ} \mathrm{C}$ to separate serum; the serum was stored at $-20^{\circ} \mathrm{C}$ ( or $-80^{\circ} \mathrm{C}$ ) until analysis.

\section{Biochemical Parameters}

The concentration of total cholesterol, high-density lipoproteins, triglycerides and glucose in blood serum was determined by colorimetric enzymatic methods applying commercial kits (Cormay, Łomianki, Poland).

\section{Genotyping}

Genotyping of six single nucleotide polymorphisms of FTO gene (rs7185735, rs9939609, rs1421085, rs1861868, rs3751812, and rs8050136) was carried out using the mass spectrometer MassARRAY ${ }^{\circledR} \quad$ Analyzer 4 (Agena Bioscience $^{\mathrm{TM}}$ ) and a QuantStudio TM 3D Digital PCR System Life Technologies (Applied Biosystems) amplifier using TaqMan Validated SNP Genotyping Assay kits (Applied Biosystems), on the base The Core Facility "Medical Genomics", Tomsk NRMC. The criteria for selecting the variants mentioned were a) their citation in the relevant scientific literature as described in the introduction and $\mathrm{b}$ ) a minor allele frequency (MAF) of at least 5\%. Basic information of these SNPs is described in Supplementary Table 1.

\section{Statistical Procedures}

The analysis was carried out with software R version 4.0.4 using standard functions, as well as additional packages "SNPassoc", "psych" and "dplyr". The Hardy-Weinberg equilibrium (HWE) of genotypic frequencies was tested by the chi-square test. Pearson's chi-squared test was used for the between-group comparison of genotypic and allelic frequencies at the significance level $p<0.05$. Assessment of the association of genotypes and alleles of the studied polymorphic variants of genes with a pathological phenotype was carried out using the odds ratio (OR) with a $95 \%$ confidence interval for the odds ratio $(95 \% \mathrm{CI})$.

Logistic regression analysis was performed via standard "glm" function in R environment. Assessment of linkage disequilibrium and haplotype analysis was performed by Haploview software. The standardized measure of linkage disequilibrium (D') based on Lewontin. ${ }^{59}$ The high linkage between loci has accorded to $D^{\prime}=1$ and LOD $\geq 2$ (LOD-score; logarithm of odds ratio). Blocks were identified by the Solid Spine algorithm. To count the frequencies of haplotypes, we used EM-algorithm, which is realized in Haploview software.

\section{Results}

A total of 517 patients receiving long-term antipsychotic therapy were examined. Table 1 presents the main demographic and clinical parameters of the studied patients. 
Table I Demographic and Clinical Parameters of the Studied Patients

\begin{tabular}{|l|l|}
\hline Sample Size, $\mathbf{n}$ & $\mathbf{5}$ I7 \\
\hline Gender, n (\%) & $\begin{array}{l}\text { Men: 269 (52.0\%) } \\
\text { Women: 248 (48.0\%) }\end{array}$ \\
\hline Age, years, Me [QI; Q3] & 39 [3I; 49] \\
\hline Age at onset, years, Me [QI;Q3] & 24 [20; 30] \\
\hline Duration of illness, years, Me [QI; Q3] & I3 [7; 2I] \\
\hline PANSS, Me [QI;Q3] & $\begin{array}{l}\text { PANSS total score: I00 [88; } \\
\text { II0] } \\
\text { PANSS negative score: 25 } \\
{[21 ; 28]} \\
\text { PANSS positive score: 22 } \\
\text { [I8;26] } \\
\text { PANSS general score: 52 } \\
\text { [44;58] }\end{array}$ \\
\hline Duration of taking antipsychotics, & 9 [3;17] \\
years, Me [QI;Q3] & $\begin{array}{l}\text { Atypical antipsychotics: 199 } \\
(38.5 \%)\end{array}$ \\
\hline CPZeq, dose, mg, Me [QI; Q3] & 450 [230;750] \\
\hline Antipsychotics generations, n (\%) & Conventional antipsychotics: \\
\hline
\end{tabular}

Note: Me [QI; Q3] - median and quartiles (first and third).

Abbreviation: CPZeq, chlorpromazine equivalents.

According to the criteria of the IDF (2005), metabolic syndrome was diagnosed in 139 patients (26.9\%). Patients with metabolic syndrome had an older age and a longer duration of the disease (Table 2).

Checking the frequency distribution of genotypes in the study group of patients showed that the frequency distribution corresponds to the Hardy-Weinberg equilibrium except for rs7185735 polymorphism (Supplementary Table 2). This polymorphism was excluded from further analysis.

None of the polymorphisms studied showed a significant association with the presence of metabolic syndrome (Supplementary Table 3).

We divided the patients' group into two groups: patients with and without abdominal obesity according to the definition of abdominal obesity according to IDF (2005) criteria (waist circumference more than $94 \mathrm{~cm}$ in men, more than $80 \mathrm{~cm}$ in women). Our results demonstrate the tendency to the statistical association between genotypes frequency rs9939609 and rs1421085 and abdominal obesity $(\mathrm{p}=0.051$ and $\mathrm{p}=0.052$ accordantly). (Supplementary Table 4) However, this tendency was
Table 2 Demographic and Clinical Parameters of Patients with and without MetS

\begin{tabular}{|c|c|c|c|c|}
\hline \multicolumn{2}{|c|}{ Parameter } & $\begin{array}{c}\text { Patients } \\
\text { without } \\
\text { MetS, } n=378 \\
\text { (73.1\%) }\end{array}$ & $\begin{array}{c}\text { Patients } \\
\text { with MetS, } \\
n=139 \\
(26.9 \%)\end{array}$ & p value \\
\hline $\begin{array}{l}\text { Gender, } \\
\mathrm{n}(\%)\end{array}$ & $\begin{array}{l}\text { Women } \\
\text { Men }\end{array}$ & $\begin{array}{l}165(43.7 \%) \\
213(56.3 \%)\end{array}$ & $\begin{array}{l}83(59.8 \%) \\
56(40.2 \%)\end{array}$ & 0.001 \\
\hline \multicolumn{2}{|c|}{$\begin{array}{l}\text { Age, years, Me [QI; } \\
\text { Q3] }\end{array}$} & $37[30 ; 47]$ & $44[34 ; 54]$ & 0.000025 \\
\hline \multicolumn{2}{|c|}{$\begin{array}{l}\text { Duration of illness, } \\
\text { years, Me [QI; Q3] }\end{array}$} & $12[6 ; 20]$ & $17[9 ; 23]$ & 0.0007 \\
\hline \multicolumn{2}{|c|}{$\begin{array}{l}\text { CPZeq, dose, mg, } \\
\text { Me [QI; Q3] }\end{array}$} & $450[250 ; 750]$ & $\begin{array}{c}434.8 \\
{[225 ; 687.5]}\end{array}$ & 0.962 \\
\hline \multicolumn{2}{|c|}{$\begin{array}{l}\text { Body mass index } \\
\text { (BMI), Me [QI; Q3] }\end{array}$} & $23[21.2 ; 26.3]$ & $\begin{array}{c}30.5 \\
{[26.9 ; 34.4]}\end{array}$ & $<0.0001$ \\
\hline \multicolumn{2}{|c|}{$\begin{array}{l}\text { Waist } \\
\text { circumference, cm, } \\
\text { Me [QI; Q3] }\end{array}$} & $83[76 ; 90]$ & $102[95 ; 110]$ & $<0.0001$ \\
\hline
\end{tabular}

Notes: Me [QI; Q3] - median and quartiles (first and third); in bold: significant difference.

Abbreviation: CPZeq, chlorpromazine equivalents.

lost after correcting for differences in gender, age and duration of illness.

Results of associative analysis genotypes/alleles frequency and body mass index in patients with schizophrenia show that all variants were significantly associated with BMI apart from rs1861868 (Table 3). The logistic regression with adjustment for covariates was applied to test for association between the SNPs and BMI. Age, gender and duration of schizophrenia were used as covariates, and significant effects for rs9939609, rs1421085, rs3751812 and rs8050136 remained.

The next step in our data analysis was to assess linkage disequilibrium and make a haplotype analysis. Strong linkage was identified in Block 1 between four SNPs of the FTO gene (Figure 1). Haplotypes TCGT and CATA were associated with increased BMI in patients with schizophrenia and may have a linkage through heredity.

Then, we performed association tests for haplotypes and BMI based on observed frequencies and applied permutation test $(10,000$ times) to assess how real significance of our results in haplotypes (Table 4).

After the permutation test, all significances were gone, except TCGT-haplotype, which shows the best values, and we can conclude about the tendency to associate this haplotype with BMI. Possibly, further studies with more 
Table 3 Results of Associative Analysis Genotypes/Alleles Frequency and Body Mass Index in Patients with Schizophrenia

\begin{tabular}{|c|c|c|c|c|c|c|c|c|c|c|}
\hline SNP & $\begin{array}{l}\text { Genotypes/ } \\
\text { Alleles }\end{array}$ & $\begin{array}{l}\text { Patients with } \\
\text { BMI } \leq \mathbf{2 5}\end{array}$ & $\%$ & $\begin{array}{l}\text { Patients with } \\
\text { BMI > } 25\end{array}$ & $\%$ & OR & $\begin{array}{l}\text { Cl 95\% } \\
\text { (Lower) }\end{array}$ & $\begin{array}{l}\text { Cl 95\% } \\
\text { (Upper) }\end{array}$ & $\chi^{2}$ & $P$ \\
\hline \multirow[t]{5}{*}{ rs9939609 } & $T / T$ & 75 & 30.4 & 55 & 24 & 0.72 & 0.48 & 1.09 & 7.989 & 0.018 \\
\hline & $\mathrm{T} / \mathrm{A}$ & 136 & 55.1 & 122 & 53.3 & 1.22 & 0.8 & 1.87 & & \\
\hline & $\mathrm{A} / \mathrm{A}$ & 36 & 14.6 & 52 & 22.7 & 1.97 & 1.14 & 3.41 & & \\
\hline & $T$ & 0.579 & - & 0.507 & - & 0.75 & 0.58 & 0.96 & 5.022 & 0.025 \\
\hline & $A$ & 0.421 & - & 0.493 & - & 1.34 & 1.04 & 1.73 & & \\
\hline \multirow[t]{5}{*}{ rs/42/085 } & $T / T$ & 83 & 33.6 & 60 & 25.9 & 0.69 & 0.46 & 1.02 & 6.859 & 0.032 \\
\hline & $\mathrm{T} / \mathrm{C}$ & 123 & 49.8 & 120 & 51.7 & 1.35 & 0.89 & 2.05 & & \\
\hline & $\mathrm{C} / \mathrm{C}$ & 41 & 16.6 & 52 & 22.4 & 1.75 & 1.04 & 2.97 & & \\
\hline & $\mathrm{T}$ & 0.585 & - & 0.517 & - & 0.76 & 0.59 & 0.98 & 4.445 & 0.035 \\
\hline & C & 0.415 & - & 0.483 & - & 1.32 & 1.02 & 1.70 & & \\
\hline \multirow[t]{5}{*}{$r s / 86 / 868$} & $\mathrm{C} / \mathrm{C}$ & 83 & 33.6 & 64 & 27.6 & 0.75 & 0.51 & 1.11 & 0.608 & 0.738 \\
\hline & $\mathrm{C} / \mathrm{T}$ & 117 & 47.4 & 133 & 57.3 & 1.47 & 0.98 & 2.22 & & \\
\hline & $T / T$ & 47 & 19 & 35 & 15.1 & 0.97 & 0.56 & 1.67 & & \\
\hline & C & 0.573 & - & 0.563 & - & 0.96 & 0.74 & 1.24 & 0.105 & 0.746 \\
\hline & $\mathrm{T}$ & 0.427 & - & 0.438 & - & 1.04 & 0.81 & 1.35 & & \\
\hline \multirow[t]{5}{*}{$r s 375 / 812$} & G/G & 85 & 34.4 & 61 & 26.3 & 0.68 & 0.46 & 1.01 & 7.638 & 0.022 \\
\hline & $\mathrm{G} / \mathrm{T}$ & 126 & 51 & 123 & 53 & 1.36 & 0.9 & 2.05 & & \\
\hline & $T / T$ & 36 & 14.6 & 48 & 20.7 & 1.86 & 1.08 & 3.2 & & \\
\hline & G & 0.599 & - & 0.528 & - & 0.75 & 0.58 & 0.97 & 4.931 & 0.026 \\
\hline & $\mathrm{T}$ & 0.401 & - & 0.472 & - & 1.34 & 1.03 & 1.73 & & \\
\hline \multirow[t]{5}{*}{$r s 8050136$} & $\mathrm{C} / \mathrm{C}$ & 87 & 35.2 & 61 & 26.3 & 0.66 & 0.44 & 0.97 & 8.298 & 0.016 \\
\hline & $\mathrm{C} / \mathrm{A}$ & 124 & 50.2 & 123 & 53 & $\mathrm{I} .4 \mathrm{I}$ & 0.94 & 2.13 & & \\
\hline & $\mathrm{A} / \mathrm{A}$ & 36 & 14.6 & 48 & 20.7 & 1.9 & I.II & 3.27 & & \\
\hline & C & 0.603 & - & 0.528 & - & 0.74 & 0.57 & 0.95 & 5.514 & 0.019 \\
\hline & $A$ & 0.397 & - & 0.472 & - & 1.36 & 1.05 & 1.76 & & \\
\hline
\end{tabular}

Note: In bold: significant difference.

numbers of patients can help to investigate this haplotype completely.

\section{Discussion}

We undertook the current investigation to gain a better understanding of the possible significance of the FTO gene for the development of metabolic syndrome during (and possibly due to) the long-term use of antipsychotics. We found no relationship with metabolic syndrome itself nor with central obesity as its principal component. A relationship with BMI existed, however, and therefore presumably also with antipsychotic drug-induced body weight gain. This was more specifically true for rs9939609, rs1421085, rs3751812, and rs8050136 polymorphisms, which were also significantly related after correcting for the difference in age, gender and duration of illness. Age and duration of illness can be considered as proxies for the duration of antipsychotic drug treatment but may also contribute to the risk of developing a metabolic syndrome as such, ie for other reasons. ${ }^{60,61}$

Although this is an exploratory study, the results can be regarded as useful. To our knowledge, the variants rs1861868 and rs3751812 have not been previously studied in a population of persons with schizophrenia treated with antipsychotics. Rs 7185735 has been shown to be associated with weight gain due to antipsychotics, ${ }^{62}$ but this variant had to be disregarded due to its failure to meet the HWE criterion. With rs1421085, rs8050136 and rs9939609, the possible contribution is still obvious. A relationship with (increase in) body weight was found for rs1421085, ${ }^{63,64} \mathrm{rs} 8050136,{ }^{63,65-67}$ and rs $9939609^{62,63,66-68}$ by some authors and not by others (for rs1421085; ${ }^{66,69,70}$ resp. for rs8050136; $;^{64,69,70}$ resp. for rs9939609). ${ }^{68-73}$ These researchers, by the way, examined people with different diagnoses and ethnicities, and the medication used also showed considerable differences. Only Roffeei et al investigated the relationship with metabolic 


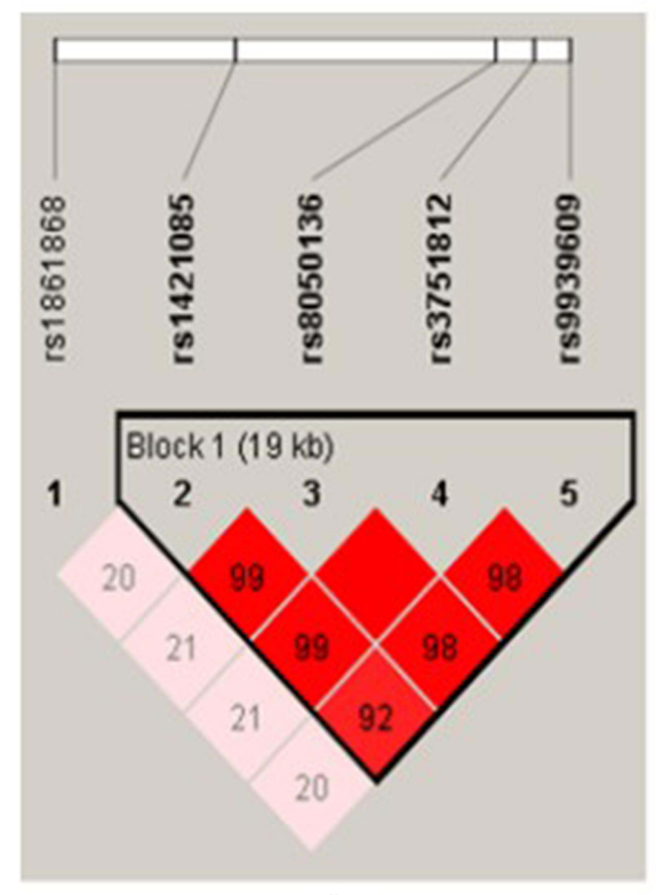

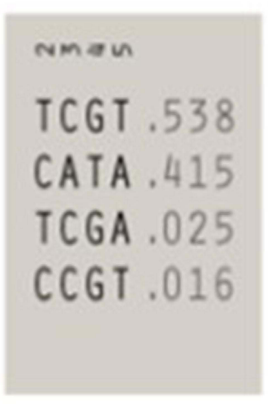

B

Figure I (A) Structure of linkage disequilibrium, investigated between 5 SNPs of FTO gene for patients with schizophrenia with metabolic syndrome. (B) Identified haplotypes in Block I with frequencies.

Notes: colour scheme is in accordance with official documentation; $D^{\prime}=1$ and LOD $\geq 2-$ strong linkage (bright red); $D^{\prime}<1$ and LOD $>2-$ average strength of linkage (shades of pink/red); D' $<1$ and LOD<2 - weak linkage (white colour).

syndrome and found an association with rs9939609 with Malaysian persons with schizophrenia who were treated with antipsychotics. ${ }^{52}$

The exact nature of the involvement of Fat Mass and Obesity Associated (FTO) Gene in the development of the metabolic syndrome from the use of antipsychotics in schizophrenia patients is unclear. It has been suggested that the FTO gene would mainly influence the differentiation of white and beige adipocytes during early embryological development. $^{34}$ This is an attractive thought, as it could explain why some individuals may be prone to overweight from an early age regardless of environmental influences. An excess of white (energy-storing) adipocytes could cause that the effects of (second generation) antipsychotics more easily result in body weight gain regardless of its localization (which is mainly reflected by BMI), only intra-abdominal fat contributes to metabolic syndrome by increasing waist circumference. This is somehow consistent with our findings; obesity itself seems to be associated with variations in the FTO gene, but metabolic syndrome (which is mainly determined by waist circumference and possible metabolic consequences of obesity) is not.

Although our study included a far larger number of patients than other research groups, it has several limitations. We applied an observational and transsectional design, our patients were treated with a variety of first and/or second generation antipsychotic drugs, and we cannot be certain about the previous long-term stability of drug intake causing the metabolic effects. However, in combination with the results of other researchers, our study provides a good indication that variants of the FTO gene only indirectly influence the development of the metabolic syndrome.

Table 4 Results of Association Test Between Haplotypes and BMI in Patients with Schizophrenia

\begin{tabular}{|l|c|c|c|c|c|c|}
\hline Haplotype/Block I & Frequencies & Case, Control Frequencies & $\chi^{\mathbf{2}}$ & P & $\chi^{\mathbf{2}}$-Perm & p-value Perm \\
\hline TCGT & 0.538 & $0.489,0.563$ & 5.295 & 0.0214 & 5.295 & 0.0574 \\
CATA & 0.415 & $0.463,0.400$ & 3.898 & 0.0483 & 3.898 & 0.1427 \\
TCGA & 0.025 & $0.024,0.020$ & 0.148 & 0.7006 & 0.148 & 0.9935 \\
CCGT & 0.016 & $0.015,0.016$ & 0.024 & 0.8777 & 0.024 & 0.9993 \\
\hline
\end{tabular}




\section{Conclusion}

Variants rs9939609, rs1421085, rs3751812, and rs8050136 show a significant association with the body mass index of 517 people with schizophrenia who were treated with antipsychotic drugs. Statistical trends were only found with regard to the association with waist circumference (reflecting central obesity), and no association was found with the occurrence of metabolic syndrome. Combined with data published by others, our findings suggest that variations of the FTO gene have significance for the occurrence of obesity and weight gain but less directly for antipsychotic drug-induced metabolic syndrome.

\section{Acknowledgments}

The authors are grateful to the Tomsk Clinical Psychiatric Hospital (chief physician - Dr Sergey M. Andreev), the Kemerovo Regional Clinical Psychiatric Hospital (chief physician - Dr Veronika A. Sorokina) and the N.N. Solodnikova Clinical Psychiatric Hospital of Omsk (chief physician - Dr Andrey I. Cheperin) for their help in recruiting patients for this investigation.

\section{Funding}

This work was supported by the Russian Science Foundation (project no. 19-75-10012).

\section{Disclosure}

The authors report no conflicts of interest in this work.

\section{References}

1. Mitchell AJ, Vancampfort D, Sweers K, van Winkel R, Yu W, De Hert M. Prevalence of metabolic syndrome and metabolic abnormalities in schizophrenia and related disorders-a systematic review and meta-analysis. Schizophr Bull. 2013;39(2):306-318. doi:10.1093/ schbul $/$ sbr 148

2. Baller JB, McGinty EE, Azrin ST, Juliano-Bult D, Daumit GL. Screening for cardiovascular risk factors in adults with serious mental illness: a review of the evidence. BMC Psychiatry. 2015;15:55. doi:10.1186/s12888-015-0416-y

3. Hirsch L, Yang J, Bresee L, Jette N, Patten S, Pringsheim T. Secondgeneration antipsychotics and metabolic side effects: a systematic review of population-based studies. Drug Saf. 2017;40(9):771-781. doi:10.1007/s40264-017-0543-0

4. Day C. Metabolic syndrome, or what you will: definitions and epidemiology. Diab Vasc Dis Res. 2007;4(1):32-38. doi:10.3132/ dvdr.2007.003

5. Saely CH, Rein P, Drexel H. The metabolic syndrome and risk of cardiovascular disease and diabetes: experiences with the new diagnostic criteria from the International Diabetes Federation. Horm Metab Res. 2007;39(9):642-650. doi:10.1055/s-2007-985822

6. Penninx BWJH, Lange SMM. Metabolic syndrome in psychiatric patients: overview, mechanisms, and implications. Dialogues Clin Neurosci. 2018;20(1):63-73. doi:10.31887/DCNS.2018.20.1/bpenninx
7. Howell S, Yarovova E, Khwanda A, Rosen SD. Cardiovascular effects of psychotic illnesses and antipsychotic therapy. Heart. 2019;105(24):1852-1859. doi:10.1136/heartjnl-2017-312107

8. Micucci C, Valli D, Matacchione G, Catalano A. Current perspectives between metabolic syndrome and cancer. Oncotarget. 2016;7 (25):38959-38972. doi:10.18632/oncotarget.8341

9. Bellastella G, Scappaticcio L, Esposito K, Giugliano D, Maiorino MI. Metabolic syndrome and cancer: "The common soil hypothesis. Diabetes Res Clin Pract. 2018;143:389-397. doi:10.1016/j.diabres. 2018.05.024

10. Tschoner A, Engl J, Laimer M, et al. Metabolic side effects of antipsychotic medication. Int J Clin Pract. 2007;61(8):1356-1370. doi:10.1111/j.1742-1241.2007.01416.x

11. Sugawara N, Yasui-Furukori N, Sato Y, et al. Prevalence of metabolic syndrome among patients with schizophrenia in Japan. Schizophr Res. 2010;123(2-3):244-250. doi:10.1016/j.schres.2010.08.030

12. Lee J, Nurjono M, Wong A, Salim A. Prevalence of metabolic syndrome among patients with schizophrenia in Singapore. Ann Acad Med Singap. 2012;41(10):457-462.

13. Tian Y, Liu D, Wang D, et al. Obesity in Chinese patients with chronic schizophrenia: prevalence, clinical correlates and relationship with cognitive deficits. Schizophr Res. 2020;215:270-276. doi:10. 1016/j.schres.2019.10.017

14. Sugai T, Suzuki Y, Yamazaki M, et al. High prevalence of obesity, hypertension, hyperlipidemia, and diabetes mellitus in Japanese outpatients with schizophrenia: a nationwide survey. PLoS One. 2016;11 (11):e0166429. doi:10.1371/journal.pone.0166429

15. van der Hoeven F, Schimmang T, Volkmann A, Mattei MG, Kyewski B, Rüther U. Programmed cell death is affected in the novel mouse mutant Fused toes (Ft). Development. 1994;120 (9):2601-2607. doi:10.1242/dev.120.9.2601

16. Peters T, Ausmeier K, Rüther U. Cloning of Fatso (Fto), a novel gene deleted by the Fused toes (Ft) mouse mutation. Mamm Genome. 1999;10(10):983-986. doi:10.1007/s003359901144

17. Frayling TM, Timpson NJ, Weedon MN, et al. A common variant in the FTO gene is associated with body mass index and predisposes to childhood and adult obesity. Science. 2007;316(5826):889-894. doi:10.1126/science. 1141634

18. Scuteri A, Sanna S, Chen WM, et al. Genome-wide association scan shows genetic variants in the FTO gene are associated with obesity-related traits. PLoS Genet. 2007;3(7):e115. doi:10.1371/journal.pgen.0030115

19. Loos RJ, Bouchard C. FTO: the first gene contributing to common forms of human obesity. Obes Rev. 2008;9(3):246-250. doi:10.1111/ j.1467-789X.2008.00481.x

20. Fawcett KA, Barroso I. The genetics of obesity: FTO leads the way. Trends Genet. 2010;26(6):266-274. doi:10.1016/j.tig.2010.02.006

21. Gerken T, Girard CA, Tung YC, et al. The obesity-associated FTO gene encodes a 2-oxoglutarate-dependent nucleic acid demethylase. Science. 2007;318(5855):1469-1472. doi:10.1126/science.1151710

22. Jia G, Fu Y, Zhao X, et al. N6-methyladenosine in nuclear RNA is a major substrate of the obesity-associated FTO. Nat Chem Biol. 2011;7(12):885-887. doi:10.1038/nchembio.687

23. Fischer J, Koch L, Emmerling C, et al. Inactivation of the Fto gene protects from obesity. Nature. 2009;458(7240):894-898. doi:10.1038/ nature 07848

24. Gao X, Shin YH, Li M, Wang F, Tong Q, Zhang P. The fat mass and obesity associated gene FTO functions in the brain to regulate postnatal growth in mice. PLoS One. 2010;5(11):e14005. doi:10.1371/ journal.pone.0014005

25. Church C, Moir L, McMurray F, et al. Overexpression of Fto leads to increased food intake and results in obesity. Nat Genet. 2010;42 (12):1086-1092. doi:10.1038/ng.713

26. Zhou Y, Kong Y, Fan W, et al. Principles of RNA methylation and their implications for biology and medicine. Biomed Pharmacother. 2020;131:110731. doi:10.1016/j.biopha.2020.110731 
27. He PC, He C. m6 A RNA methylation: from mechanisms to therapeutic potential. EMBOJ. 2021;40(3):e105977. doi:10.15252/embj.2020105977

28. Ganeff IMM, Bos MM, van Heemst D, Noordam R. BMI-associated gene variants in FTO and cardiometabolic and brain disease: obesity or pleiotropy? Physiol Genomics. 2019;51(8):311-322. doi:10.1152/ physiolgenomics.00040.2019

29. Annapoorna PK, Iyer H, Parnaik T, Narasimhan H, Bhattacharya A, Kumar A. FTO: an emerging molecular player in neuropsychiatric diseases. Neuroscience. 2019;418:15-24. doi:10.1016/j.neuroscience. 2019.08.021

30. Lan N, Lu Y, Zhang Y, et al. FTO - a common genetic basis for obesity and cancer. Front Genet. 2020;11:559138. doi:10.3389/ fgene. 2020.559138

31. Dina C, Meyre D, Gallina S, et al. Variation in FTO contributes to childhood obesity and severe adult obesity. Nat Genet. 2007;39 (6):724-726. doi:10.1038/ng2048

32. Herman MA, Rosen ED. Making biological sense of GWAS data: lessons from the FTO locus. Cell Metab. 2015;22(4):538-539. doi:10.1016/j.cmet.2015.09.018

33. Smemo S, Tena JJ, Kim KH, et al. Obesity-associated variants within FTO form long-range functional connections with IRX3. Nature. 2014;507(7492):371-375. doi:10.1038/nature13138

34. Claussnitzer M, Dankel SN, Kim KH, et al. FTO obesity variant circuitry and adipocyte browning in humans. $N$ Engl J Med. 2015;373 (10):895-907. doi:10.1056/NEJMoa1502214

35. Tóth BB, Arianti R, Shaw A, et al. FTO intronic SNP strongly influences human neck adipocyte browning determined by Tissue and PPAR $\gamma$ specific regulation: a transcriptome analysis. Cells. 2020;9(4):987. doi:10.3390/cells9040987

36. Bjune JI, Dyer L, Røsland GV, et al. The homeobox factor Irx3 maintains adipogenic identity. Metabolism. 2020;103:154014. doi:10.1016/j.metabol.2019.154014

37. Villalobos-Comparán M, Teresa Flores-Dorantes M, Teresa Villarreal-Molina M, et al. The FTO gene is associated with adulthood obesity in the Mexican population. Obesity (Silver Spring). 2008;16(10):2296-2301. doi:10.1038/oby.2008.367

38. Andreasen CH, Stender-Petersen KL, Mogensen MS, et al. Low physical activity accentuates the effect of the FTO rs9939609 polymorphism on body fat accumulation. Diabetes. 2008;57(1):95-101. doi:10.2337/db07-0910

39. Ran S, Jiang ZX, He X, et al. Replication of FTO gene associated with lean mass in a meta-analysis of Genome-Wide Association Studies. Sci Rep. 2020;10(1):5057. doi:10.1038/s41598-020-61406-3

40. Locke AE, Kahali B, Berndt SI, et al. Genetic studies of body mass index yield new insights for obesity biology. Nature. 2015;518 (7538):197-206. doi:10.1038/nature14177

41. Rampersaud E, Mitchell BD, Pollin TI, et al. Physical activity and the association of common FTO gene variants with body mass index and obesity. Arch Intern Med. 2008;168(16):1791-1797. doi:10.1001/ archinte.168.16.1791

42. Rodríguez-López R, González-Carpio M, Serrano MV, et al. Asociación de polimorfismos en el gen FTO con la obesidad mórbida en la población extremeña [Association of FTO gene polymorphisms and morbid obesity in the population of Extremadura (Spain)]. Endocrinol Nutr. 2010;57(5):203-209. doi:10.1016/j.endonu.2010.03.002

43. Tönjes A, Zeggini E, Kovacs P, et al. Association of FTO variants with BMI and fat mass in the self-contained population of Sorbs in Germany. Eur J Hum Genet. 2010;18(1):104-110. doi:10.1038/ejhg.2009.107

44. Tan LJ, Zhu H, He H, et al. Replication of 6 obesity genes in a metaanalysis of genome-wide association studies from diverse ancestries. PLoS One. 2014;9(5):e96149. doi:10.1371/journal.pone.0096149

45. Khan SM, El Hajj Chehadeh S, Abdulrahman M, Osman W, Al Safar H. Establishing a genetic link between FTO and VDR gene polymorphisms and obesity in the Emirati population. BMC Med Genet. 2018;19(1):11. doi:10.1186/s12881-018-0522-z
46. Al Asoom LI, Al Afandi DT, Al Abdulhadi AS, Rafique N, Chathoth S, Al Sunni AA. Protective association of single nucleotide polymorphisms rs1861868-FTO and rs7975232-VDR and obesity in Saudi females. Int J Gen Med. 2020;13:235-241. doi:10.2147/JJGM.S251466

47. Reynolds GP. Pharmacogenetic aspects of antipsychotic drug-induced weight gain - a critical review. Clin Psychopharmacol Neurosci. 2012;10(2):71-77. doi:10.9758/cpn.2012.10.2.71

48. Kao AC, Muller DJ. Genetics of antipsychotic-induced weight gain: update and current perspectives. Pharmacogenomics. 2013;14 (16):2067-2083. doi:10.2217/pgs.13.207

49. Malan-Müller S, Kilian S, van den Heuvel LL, et al. A systematic review of genetic variants associated with metabolic syndrome in patients with schizophrenia. Schizophr Res. 2016;170(1):1-17. doi:10.1016/j.schres.2015.11.011

50. Luo C, Liu J, Wang X, Mao X, Zhou H, Liu Z. Pharmacogenetic correlates of antipsychotic-induced weight gain in the Chinese population. Neurosci Bull. 2019;35(3):561-580. doi:10.1007/s12264-018-0323-6

51. Corfitsen HT, Krantz B, Larsen A, Drago A. Molecular pathway analysis associates alterations in obesity-related genes and antipsychotic-induced weight gain. Acta Neuropsychiatr. 2020;32 (2):72-83. doi:10.1017/neu.2019.41

52. Roffeei SN, Mohamed Z, Reynolds GP, et al. Association of FTO, LEPR and MTHFR gene polymorphisms with metabolic syndrome in schizophrenia patients receiving antipsychotics. Pharmacogenomics. 2014;15(4):477-485. doi:10.2217/pgs.13.220

53. Kornetova EG, Kornetov AN, Mednova IA, et al. Comparative characteristics of the metabolic syndrome prevalence in patients with schizophrenia in three western Siberia psychiatric hospitals. Front Psychiatry. 2021;12:661174. doi:10.3389/fpsyt.2021.661174

54. Paderina DZ, Boiko AS, Pozhidaev IV, et al. Genetic polymorphisms of 5-HT receptors and antipsychotic-induced metabolic dysfunction in patients with schizophrenia. J Pers Med. 2021;11(3):181. doi:10.3390/jpm11030181

55. World Health Organization. International Statistical Classification of Diseases and Health Related Problems ICD-10. Geneva, VH: World Health Organization; 2004.

56. Kay SR, Fiszbein A, Opler LA. The positive and negative syndrome scale (PANSS) for schizophrenia. Schizophr Bull. 1987;13 (2):261-276. doi:10.1093/schbul/13.2.261

57. Andreasen NC, Pressler M, Nopoulos P, Miller D, Ho BC. Antipsychotic dose equivalents and dose-years: a standardized method for comparing exposure to different drugs. Biol Psychiatry. 2010;67(3):255-262. doi:10.1016/j.biopsych.2009.08.040

58. Alberti KG, Zimmet P, Shaw J. Metabolic syndrome-a new worldwide definition. A consensus statement from the International Diabetes Federation. Diabet Med. 2006;23(5):469-480. doi:10.1111/ j.1464-5491.2006.01858.x

59. Lewontin RC. The interaction of selection and linkage. I. general considerations; heterotic models. Genetics. 1964;49(1):49-67. doi:10.1093/genetics/49.1.49

60. Márquez-Sandoval F, Macedo-Ojeda G, Viramontes-Hörner D, Fernández Ballart JD, Salas Salvadó J, Vizmanos B. The prevalence of metabolic syndrome in Latin America: a systematic review. Public Health Nutr. 2011;14(10):1702-1713. doi:10.1017/S1368980010003320

61. Pucci G, Alcidi R, Tap L, Battista F, Mattace-Raso F, Schillaci G. Sex- and gender-related prevalence, cardiovascular risk and therapeutic approach in metabolic syndrome: a review of the literature. Pharmacol Res. 2017;120:34-42. doi:10.1016/j.phrs.2017.03.008

62. Schröder C, Czerwensky F, Leucht S, Steimer W. Fat mass and obesity-related gene variants rs 9939609 and rs7185735 are associated with second-generation antipsychotic-induced weight gain. Pharmacopsychiatry. 2019;52(1):16-23. doi:10.1055/s-0043-125392

63. Huang MC, Kao CF, Chiu CC, et al. The genetic association of FTO variants with metabolic traits in patients with schizophrenia may be modified by antipsychotics. J Clin Psychopharmacol. 2014;34 (1):162-165. doi:10.1097/JCP.0b013e3182a95b20 
64. Gassó P, Arnaiz JA, Mas S, et al. Association study of candidate genes with obesity and metabolic traits in antipsychotic-treated patients with first-episode psychosis over a 2-year period. $J$ Psychopharmacol. 2020;34(5):514-523. doi:10.1177/0269881120 903462

65. Wang F, Mi W-F, Lu T-L, Ruan -Y-Y, Zhang D, Yue W-H. Association study of FTO gene polymorphism with weight gain associated with 4 week risperidone treatment. Chin Ment Health J. 2013;27(2):157-160.

66. Song X, Pang L, Feng Y, et al. Fat-mass and obesity-associated gene polymorphisms and weight gain after risperidone treatment in first episode schizophrenia. Behav Brain Funct. 2014;10(1):35. doi:10. 1186/1744-9081-10-35

67. Díaz-Anzaldúa A, Ocampo-Mendoza Y, Hernández-Lagunas JO, et al. Differences in body mass index according to fat mass- and obesity-associated (FTO) genotype in Mexican patients with bipolar disorder. Bipolar Disord. 2015;17(6):662-669. doi:10.1111/bdi.12328

68. Reynolds GP, Yevtushenko OO, Gordon S, Arranz B, San L, Cooper SJ. The obesity risk gene FTO influences body mass in chronic schizophrenia but not initial antipsychotic drug-induced weight gain in first-episode patients. Int J Neuropsychopharmacol. 2013;16(6):1421-1425. doi:10.1017/S1461145712001435
69. Nurmi EL, Spilman SL, Whelan F, et al. Moderation of antipsychotic-induced weight gain by energy balance gene variants in the RUPP autism network risperidone studies. Transl Psychiatry. 2013;3(6):e274. doi:10.1038/tp.2013.26

70. Shing EC, Tiwari AK, Brandl EJ, et al. Fat mass- and obesity-associated (FTO) gene and antipsychotic-induced weight gain: an association study. Neuropsychobiology. 2014;69(1):59-63. doi:10.1159/000356231

71. Jassim G, Fernø J, Theisen FM, et al. Association study of energy homeostasis genes and antipsychotic-induced weight gain in patients with schizophrenia. Pharmacopsychiatry. 2011;44(1):15-20. doi:10. 1055/s-0030-1263174

72. Watanabe SY, Iga J, Numata S, et al. Association study of fat-mass and obesity-associated gene and body mass index in Japanese patients with schizophrenia and healthy subjects. Clin Psychopharmacol Neurosci. 2012;10(3):185-189. doi:10.9758/ cpn.2012.10.3.185

73. de Silva VA, Muneeswaran K, Ratnatunga SS, et al. Genetic association between antipsychotic induced weight gain and FTO gene in a Sri Lankan population. Ceylon Med J. 2019;64(2):40-45. doi:10. 4038/cmj.v64i2.8889

\section{Publish your work in this journal}

Pharmacogenomics and Personalized Medicine is an international, peer-reviewed, open access journal characterizing the influence of genotype on pharmacology leading to the development of personalized treatment programs and individualized drug selection for improved safety, efficacy and sustainability. This journal is indexed on the American Chemical Society's Chemical Abstracts Service (CAS). The manuscript management system is completely online and includes a very quick and fair peer-review system, which is all easy to use. Visit http://www.dovepress.com/testimonials.php to read real quotes from published authors. 